\title{
COLORADOSCHOOLOFMINES
}

EARTH•ENERGY•ENVIRONMENT

Division OF ECONOMICS AND BUSINESS

WORKING PAPER SERIES

\section{Carbon content of electricity futures in Phase II of the EU ETS}

\author{
Harrison Fell \\ Beat Hintermann \\ Herman Vollebergh
}

\author{
Working Paper 2013-06 \\ http: //econbus . mines . edu/working-papers/wp201306.pdf \\ Colorado School of Mines \\ Division of Economics and Business \\ 1500 Illinois Street \\ Golden, CO 80401
}

August 2013

(c) 2013 by the listed authors. All rights reserved. 
Colorado School of Mines

Division of Economics and Business

Working Paper No. 2013-06

August 2013

Title:

Carbon content of electricity futures

in Phase II of the EU ETS

Author(s):

Harrison Fell

Division of Economics and Business

Colorado School of Mines

Golden, CO 80401-1887

hfell@mines.edu

Beat Hintermann

Faculty of Business and Economics

University of Basel

b.hintermann@unibas.ch

Herman Vollebergh

PBL Nethererlands Environmental Assessment Agency

Herman.Vollebergh@pbl.nl

\begin{abstract}
We estimate the relationship between electricity, fuel and carbon prices in Germany, France, the Netherlands, the Nord Pool market and Spain, using one-year futures for base and peak load prices for the years 2009-2012, corresponding to physical settlement during the second market phase of the EU ETS. We employ a series of estimation methods that allow for an increasing interaction between electricity and input prices on the one hand, and between electricity markets on the other. The results vary by country due to different generation portfolios. Overall, we find that (a) carbon costs are passed through fully in most countries, and perhaps even by more than 100\%; (b) under some model specifications, cost pass-through is similar during peak and during base load for France, Germany and the Netherlands; and (c) the results are sensitive to the degree of crosscommodity and cross-market interaction allowed. We further find that coal prices are negatively and gas prices are positively associated with allowance prices, although the latter effect is not statistically significant in all specifications.
\end{abstract}




\section{Introduction}

Thermal electricity from fossil sources generates $\mathrm{CO}_{2}$ emissions as a by-product, and carbon policies aim to internalize the social cost of emissions by placing a price on them. If emissions are costly, they should be treated like any other input for electricity generation such as labor, capital and fuel. The costs of emitting $\mathrm{CO}_{2}$ are thus passed through to the ultimate "polluters", i.e. the consumers who demand energy-intensive goods. The degree to which carbon costs are passed forward to electricity prices depends on market conditions (e.g. the degree of competition and consumers' demand response), and is important to determine the full distributional costs of climate policy, as well as its effect. For example, if carbon prices are not fully reflected in output prices, producers will pay more of the bill, while consumers would have less incentive to re-allocate consumption towards less emission-intensive products.

One important recent example where incidence effects gave rise to a heated debate is the "cost pass-through" discussion on EU ETS. ${ }^{1}$ The debate started with a report by Sijm et al. (2006), which covers peak and base load estimates for Germany and the Netherlands using data for the first half year of $2005 .^{2}$ Sijm et al. (2008) extend the analysis to seven other EU ETS countries and a longer period. Both studies find positive passthrough rates for most countries, which is consistent with the interpretation of carbon as an opportunity cost. ${ }^{3}$ The approach taken in these studies consists of applying a relatively simple econometric OLS framework to electricity spreads, which implies a series of restrictive assumptions. First, the price-setting generation technology is imposed a priori by using either the dark or the spark spread, although the true marginal generator may change every hour (or even half-hour in some markets). Second, this type of analysis

\footnotetext{
${ }^{1}$ The European Union introduced the EU Emissions Trading Scheme (ETS) in 2005, which places a cap on aggregate emissions from the most energy-intensive industrial sectors. In the first two market phases, firms received allocations mostly at no cost. The general public took issue with the fact that firms raised their output prices despite free allowance allocation, reaping so-called "windfall profits". Providing allowances for free implies that the polluters receive the scarcity rent, whereas sound reasons exist to distribute these rents differently (Bovenberg and Goulder, 2000).

${ }^{2}$ Smale et al. (2006) focused on the other sectors covered by the EU ETS and found positive but smaller cost pass-through rates that varied with the degree of a sector's exposure to competition from firms outside the EU. Due to transmission constraints, outside competition is almost zero for the power sector.

${ }^{3}$ Under perfect competition, cost pass-through is identical for taxes and permits, and is independent of the method of permit allocation. If firms perceive market power in the permit market and take the permit-output market interaction into account, the choice of allocation will influence the market outcome because firms take cost pass-through into account when maximizing their profits (Hintermann, 2011). A number of simulation studies have studied carbon cost pass-through under different market structures; see e.g. Lise et al. (2010) and references therein.
} 
imposes complete pass-through of fuel costs while estimating the degree of carbon cost pass-through, thus creating an artificial distinction among inputs of production. Third, it does not allow for interactions between prices for electricity, input fuels and carbon; and fourth, it assumes that carbon costs are passed through either immediately or within a short time period.

It is likely that electricity and input prices are determined jointly. For instance, an increase in carbon prices may (over time) lead to a shift from coal to gas generation. This decreases the demand for coal and increases that for gas, thereby increasing the gas/coal price ratio. At the same time, the increase in electricity prices will lead to a decrease in demand in the long run, which in turn can impact the demand for $\mathrm{CO}_{2}$ permits and for input fuels. This interdependency may lead to complex and possibly prolonged adjustments of the system of prices to a shock in a particular variables. We address this by applying a vector error correction model (VECM) framework that has a dependent variable vector which includes electricity prices, emission allowance prices, and other relevant input prices.

Several papers have addressed the issue of cost pass-through by means of a cointegration framework. Fezzi and Bunn (2010) use a structural VECM that jointly models UK electricity, natural gas prices, and EU-ETS allowance (EUA) prices over Phase I of the EU-ETS. Their results imply that electricity and input prices are in fact cointegrated and find that a $1 \%$ increase in EUA prices led to a $0.32 \%$ long-run increase in UK electricity prices. Similarly, Fell (2010) carries out a VECM analysis of the Nordic electricity market (Nord Pool) for the years 2005-2008 using a dependent variable vector that includes prices for hourly spot electricity, natural gas, coal, and EU-ETS allowances (EUAs). He reports theoretically-consistent cost pass-through rates in the short-term, but also pronounced differences between short-term and long-term price adjustments.

Zachmann and von Hirschhausen (2008) also use a cointegration framework, though in a single-equation form rather than a VECM, using futures data for 2005-2006. They argue that carbon costs are passed through asymmetrically in Germany: the response to an increase in carbon prices had an immediate positive effect on electricity prices, but carbon price decreases did not elicit an electricity price response of the same magnitude. Extending the analysis to France, Belgium and the Netherlands, Lo Prete and Norman (2012) again find evidence of cost pass-through, but not of asymmetry. 
While these papers focus on single electricity markets, Bosco et al. (2010) provide evidence that electricity prices are cointegrated across national markets. This suggests that an assessment of carbon cost pass-through in a multi-country framework may be warranted. To allow for such cross-market relationships, we use a VECM that includes one-year futures for electricity (baseload and peakload) as well as input prices and a set of control variables. We focus on electricity markets in Germany, France, the Netherlands, Nord Pool and Spain (abbreviated as DE, FR, NL, NP, and ES, respectively). A second contribution lies in our focus on market data for the delivery period 2009-2012, making our paper the first (to our knowledge) that measures the impact of Phase 2 of the EU ETS on electricity prices exclusively. Last, we compute the effect of a change in fuel prices on the allowance price and thus contribute to the growing literature of allowance price determination.

The major drawback of a multi-country, multi-commodity cointegration framework is its complexity. The impact of a shock in one variable on all other variables in the system is determined by the interaction of a series of parameters and has to be estimated using impulse-response functions (IRFs), but little economic interpretation (and therefore intuitive verification) can be attached to a single parameter estimate (see Lütkepohl, 2005). At the same time, VECMs tend to be sensitive to the choice of lags of the underlying vector autoregressive process and other specifications. The combination of high complexity and sensitivity to parameter choices implies caution in the interpretation of the results. For this reason, we also estimate cost pass-through using somewhat simpler autoregressive conditional heteroskedasticity (ARCH) approaches that treat fuel and $\mathrm{CO}_{2}$ prices as exogenous to the electricity price. We believe that by combining the results from all models we obtain a better understanding of the underlying processes than by relying on one estimation method alone.

We find that carbon costs are passed through to electricity futures, that electricity and input prices are cointegrated, and that there appear to be further cointegrating relationships between electricity prices of adjacent markets. In the specifications that do not allow for cross-market relationships, we find that the $\mathrm{CO}_{2}$ price affects electricity prices as much during peak as during base load in Germany, France and the Netherlands. For the Nordic and Spanish markets, which are only imperfectly connected to the continental European market dominated by France, Germany and the Netherlands, the results are 
more consistent with theoretical expectations when analyzing these markets separately. When allowing for market cointegration, the results are more in line with expectations. Lastly, we find that coal and natural gas price are respectively negatively and positively associated with the allowance price, although the effect of the latter is not statistically significant in all specifications.

In the next sections, we describe the theoretical relationship between carbon and electricity prices and presents our data. Section 4 contains our results, and section 5 concludes.

\section{Theoretical framework}

In a competitive wholesale electricity market, the electricity price $P$ is equal to the marginal cost of generation for the marginal generator. The marginal cost of generation will depend on input prices, including prices for non-fuel, fuel, and carbon emission allowances:

$$
P=K(R)+\eta F(R)+\psi A(R)
$$

Here, $K$ is the per-unit cost of labor, capital and other non-fuel costs, $F$ is the price for the fuel used (coal or gas), $\eta$ is the heat rate (MWh of electricity/MWh of fuel), $A$ is the $\mathrm{CO}_{2}$ allowance price, and $\psi$ is the emission intensity $\left(\mathrm{CO}_{2} / \mathrm{MWh}\right)$. The marginal generator is determined by the interplay of the demand and supply of electricity, which can be condensed into the concept of residual demand $\mathrm{R}$, defined as total electricity consumption minus nuclear and renewable generation, minus net imports. Residual demand can potentially be affected by prices for inputs as well as electricity.

We define cost pass-through as the total effect of a shock in the allowance price on the electricity price. Totally differentiating (1) and rearranging yields

$$
\begin{gathered}
\frac{d P}{d A}=\frac{\left[\psi+\eta \frac{\partial F}{\partial A}+\Gamma \frac{\partial R}{\partial A}\right]+\left(\psi \frac{\partial A}{\partial F}+\eta+\Gamma \frac{\partial R}{\partial F}\right) \frac{d F}{d A}}{1-\eta \frac{\partial F}{\partial P}-\psi \frac{\partial A}{\partial P}-\Gamma \frac{\partial R}{\partial P}} \\
\text { with } \quad \Gamma \equiv \frac{\partial K}{\partial R}+\frac{\partial \eta}{\partial R} F+\frac{\partial \psi}{\partial R} A
\end{gathered}
$$

A change in the allowance price affects the electricity price in various ways. The direct impact is measured by $\psi$, which is the effect of an allowance price change on the 
electricity price if all other prices are held constant. Any change in fuel prices and residual demand in response to the allowance price is captured by the two additional terms inside the brackets in the numerator.

If allowance and fuel prices are determined jointly, a change in fuel prices in response to a change in the allowance price will have feedback effects on residual demand and the allowance price itself. This fuel price feedback effect is represented by the terms in parenthesis. Similarly, the denominator captures the feedback effect from electricity to fuel and carbon prices; i.e. the effect that a change in electricity prices (due to the change in the allowance price) has on fuel and allowance prices, as well as on residual demand.

From (2) it becomes clear that identification of any individual effect is extremely challenging. The dependencies of non-fuel costs, heat rates and carbon intensity on residual demand that comprise $\Gamma$ are unknown and will generally differ with the level of residual demand. Likewise, the relationship between the various prices may not be constant over time and depend on price levels as well as factors outside the model, such as global demand for coal or natural gas. The relationship in (2) is further complicated by the fact that hydro generation (with the exception of run-of-river) is a control variable for electricity producers, yet it entails no marginal cost such that residual demand itself becomes endogenous. Last but not least, (2) refers to the equilibrium response of electricity prices to a shock in the allowance price, but it says nothing about the pattern of adjustments over time.

In order to deal with these difficulties, researchers make simplifying assumptions with various levels of stringency. Sijm et al. $(2008,2006)$ implicitly assume that $d F=\Gamma=$ $\partial F / \partial A=\partial F / \partial P=\partial A / \partial P=0$, which reduces (2) to $\psi$. We use a similar assumption in our ARCH approach.

Single-equation error-correction models (e.g. Zachmann and von Hirschhausen 2008) treat allowance and fuel prices as jointly determined but independent of electricity prices, which is equivalent to allowing $d F \neq 0$ in (2) but holding $\Gamma=\partial F / \partial P=\partial A / \partial P=0$. In our VECM approach, we are able to further relax the underlying assumptions by allowing the electricity price to influence input prices. The cointegration framework is difficult to directly relate to (2), but the fact that we do not allow the long-term relationship between electricity and input prices to vary with the level of residual demand is equivalent to maintaining $\Gamma=0$. 


\section{Data}

All regressions are based on weekly averages of 1-year future prices for electricity, coal, gas and EUAs. Using futures allows us to exclude contemporaneous shocks that affect electricity spot prices both on the demand side (e.g. temperature and economic activity) and on the supply side (e.g. wind, sunshine, rainfall or policy decisions). We focus on weekly averages in order to reduce noise relative to daily data, while keeping the degrees of freedom high relative to monthly data.

The drawback of using futures data is that most exchanges offer contracts for peak electricity (defined as 8 a.m. to 8 p.m. during work days) and base electricity (average of all hours), but not for individual hours. Since the marginal generator generally differs every hour, the estimated cost pass-through is based on the average pass-through of the marginal generators throughout the year. This complicates the interpretation of the coefficients, since the frequency during which the different generation technologies are on the margin is not known. For example, consider the carbon intensity of a coal-fired power plant of (roughly) $1 \mathrm{tCO}_{2} / \mathrm{MWh}$, and that of a gas-fired plant of about $0.4 \mathrm{tCO}_{2} / \mathrm{MWh}$. If we measure a cost pass-through of, say, $0.7 € / M W h$ (meaning that a $1-€$-increase in the allowance price leads to an electricity price increase of $0.7 € / \mathrm{MWh}$ in equilibrium), we cannot say whether this corresponds to a situation where coal and gas are both on the margin for $50 \%$ of the time and firms are able to fully pass through their carbon costs to consumers, or whether coal is always on the margin and firms are only able to pass on $70 \%$ of carbon costs. Using more finely defined periods would allow for a more homogeneous technology on the margin and thus lead to cleaner results, but at the cost of having to control for all contemporaneous shocks that also determine electricity prices.

Using futures data causes a second and somewhat more subtle complication. The estimated cost pass-through is based on the average pass-through of the expected marginal generator. Presumably this expectation is based on past observations, but traders may also take into account the evolving generation capacity profile of the market, which is difficult to incorporate properly. ${ }^{4}$

We use one-year electricity futures from the German (DE), French (FR), Dutch (NL),

\footnotetext{
${ }^{4}$ Note also that spot and futures prices for electricity differ not only in variance due to contemporaneous shocks, but comparing 1-year futures prices with the corresponding spot price one year later implies a futures premium of around 15\% for baseload for all countries in the sample, and around 30\% for peakload in DE, FR and NL and $12 \%$ in NP. Since electricity cannot be stored, the difference must be due to cost hedging.
} 
Nord Pool (NP) and Spanish (ES) markets, along with futures prices for coal, gas and $\mathrm{CO}_{2}$ allowances. We run all analyses separately for baseload and peakload futures, because the generation technology and thus the carbon intensity can be expected to differ. ${ }^{5}$ Although we collected futures prices from 2007-2011 (corresponding to delivery in 2008-2012), we decided to restrict the analysis to the period after the financial crisis due to convergence issues and empirically determined structural breaks in the electricity price series.

We use continuous one-year coal futures based on the the API\#2 index traded on the European Energy Exchange (EEX), because it is the most-quoted standard for hard coal entering Northwestern Europe. ${ }^{6}$ For natural gas, we use continuous one-year futures from the Title Transfer Facility (TTF), and for EUA futures we use December 2012 contracts. We accessed all price data through Thomson Reuters Datastream.

Finally, we included hydro reservoir data to allow for the possibility that a very full or very empty reservoir today may impact the next calendar year's electricity prices. We obtained reservoir level data from country providers. ${ }^{7}$

Figure 1 shows total annual generation by energy source for our five markets. The generation portfolios are quite heterogeneous and also differ somewhat between peakload and baseload. Whereas Germany, the Netherlands and Spain rely mostly on thermal generation from fossil fuels, France produces most of its electricity using nuclear energy, and the Nordic area using hydro generation. Generation by renewables other than hydro has increased in recent years, especially in Germany and Spain. Figure 2 shows that this is due to a massive expansion of solar and wind generation capacity in those countries, whereas the installed capacity of the other energy sources remained largely stable.

Note, however, that the identity of the marginal generator does not directly follow from the generation portfolios. For example, nuclear power in France is priced according to the fossil generator that would replace it, even if this generator is not running. Also, since these countries are interconnected, it is possible that the price in one market is set

\footnotetext{
${ }^{5} \mathrm{~A}$ baseload one-year future contract refers to the continuous supply of electricity during the following calendar year; the standard contract size of $1 \mathrm{MW}$ therefore translates to a contract volume of 8,760 MWh. Peakload futures refer to the electricity supply between $8 \mathrm{a} . \mathrm{m}$. and $8 \mathrm{p} . \mathrm{m}$. on weekdays, with a contract volume of 3,132 MWh. Typically, these contracts are settled financially, i.e. based on the difference between the agreed price and the average spot price during the respective delivery period.

${ }^{6}$ The API\#2 index is a CIF ARA price reference for coal imported into Europe and is the average of the Argus assessment and the McCloskey European steam coal marker. CIF is an acronym for cost, insurance and freight and means that the seller assumes the cost of shipment including insurance until the port of destination, and ARA stands for delivery in Amsterdam, Rotterdam or Antwerp.

${ }^{7}$ Available at www.nordpoolspot.com (Nord Pool area), www.rte.fr (France) and servicios3.marm.es (Spain); last accessed in April 2013.
} 
Figure 1: Electricity generation by energy source by country and year, 2008-2012

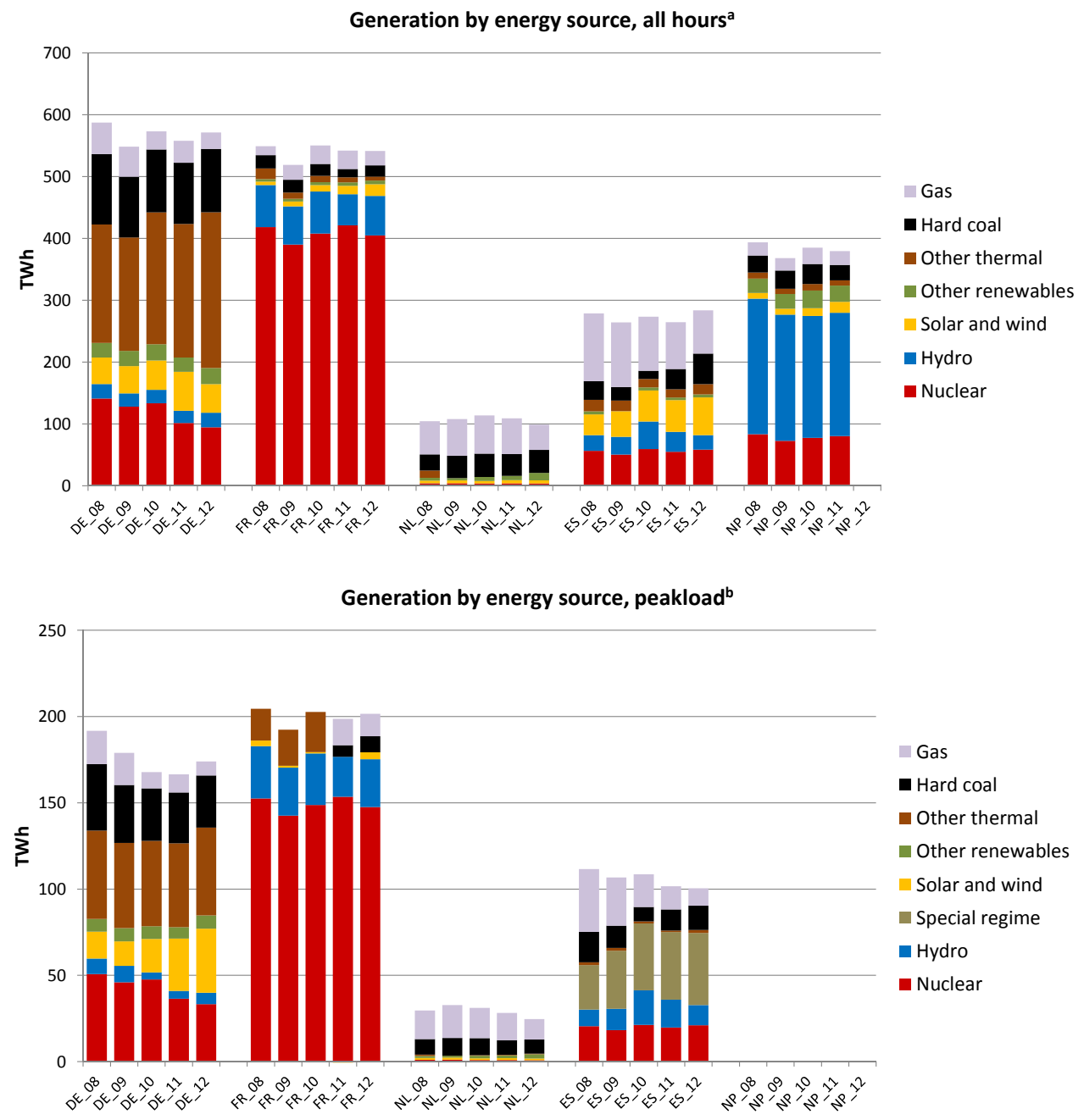

a: Source: Own graph based on data from ENTSO-E and country TSOs. "Other thermal" refers to lignite and oil in all countries except Nord Pool, where it is the sum of coal and gas (not available separately); b: Source: Own graph based on data from Point Connect and country TSOs. "Special regime" in Spain refers to renewables and cogeneration; "other thermal" in FR_08-FR_10 is sum of hard coal and natural gas; hourly production data not available for Nord Pool area.

by the marginal technology in another. Table 1 shows transmission capacities between the markets in our sample, both in terms of direct connections as well as indirect connections via third countries such as Belgium (connecting NL and FR), Denmark (connecting NP and DE) and Switzerland (connecting FR and DE).

Figure 3 displays the electricity futures for baseload (5 markets) and peakload (4 markets). Future prices are closely correlated, especially for Germany, France and the Netherlands, with somewhat lower prices in Spain (baseload prices available only) and Nord Pool. Especially peak prices for DE, FR and NL are very similar, whereas NP peak futures are significantly lower. This implies binding transmission constraints between the Nordic and continental European markets during peakload, which is consistent with the limited transmission capacity shown in Table 1. 
Figure 2: Installed generation capacity (end of year)

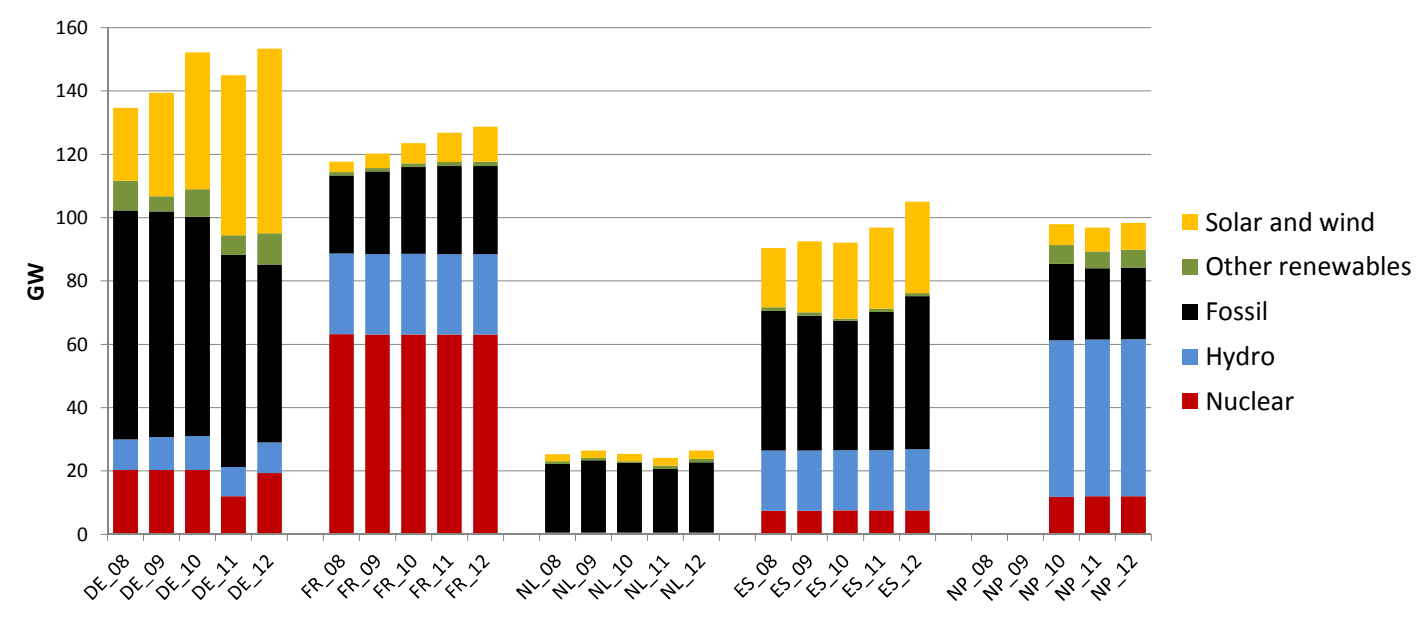

Source: Own graph based on data from ENTSO-E

Table 1: Transmission capacity in 2012 in $\mathrm{MW}^{a}$

\begin{tabular}{|c|c|c|c|c|c|c|c|c|}
\hline Exp \Imp & Belgium & France & Germany & Netherlands & Nordpool & Spain & Switzerland & Sum \\
\hline Belgium & $\mathrm{n} / \mathrm{a}$ & 800 & & 946 & & & & $1 ' 746$ \\
\hline France & 3'150 & $\mathrm{n} / \mathrm{a}$ & 1'967 & & & $1^{\prime} 450$ & 3'100 & $9^{\prime} 667$ \\
\hline Germany & & $2^{\prime} 483$ & $\mathrm{n} / \mathrm{a}$ & $2^{\prime} 449$ & 1'300 & & 953 & 7'185 \\
\hline Netherlands & 946 & & 2'166 & $\mathrm{n} / \mathrm{a}$ & 700 & & & 3'812 \\
\hline Nordpool & & & 1'286 & 700 & $\mathrm{n} / \mathrm{a}$ & & & 1'986 \\
\hline Spain & & 408 & & & & $\mathrm{n} / \mathrm{a}$ & & 408 \\
\hline Switzerland & & 1'663 & 4'000 & & & & $\mathrm{n} / \mathrm{a}$ & $5^{\prime} 663$ \\
\hline Sum & 4'096 & 5'354 & 9'419 & $4^{\prime} 095$ & $2^{\prime} 000$ & 1'450 & $4^{\prime} 053$ & $30 ' 467$ \\
\hline
\end{tabular}

a: Source: Year-ahead data from ENTSO-E; where unavailable (DE-CH \& DE-NL) we used day-ahead capacity for June 1, 2012 instead.

Figure (4) shows input prices (EUA, coal and gas) along with German power futures. We scaled some of the series to provide a visual indication of cointegration across and within markets, which is confirmed by our cointegration tests.

\section{Estimation results}

In the following we present our estimation models and the corresponding results. We start with exogenously determined input prices and independent electricity markets and then gradually relax these assumptions.

\subsection{Cost pass-through with exogenous input prices}

If we assume that input prices are exogenous to electricity prices and each other, the most natural way to estimate cost pass-through is to regress electricity prices from individual markets $\left(P_{t}\right)$ on prices for coal $\left(C_{t}\right)$, natural gas $\left(G_{t}\right)$ and $\mathrm{CO}_{2}$ allowances $\left(A_{t}\right)$. To allow 
Figure 3: Year-ahead futures for baseload (left) and peakload (right) electricity
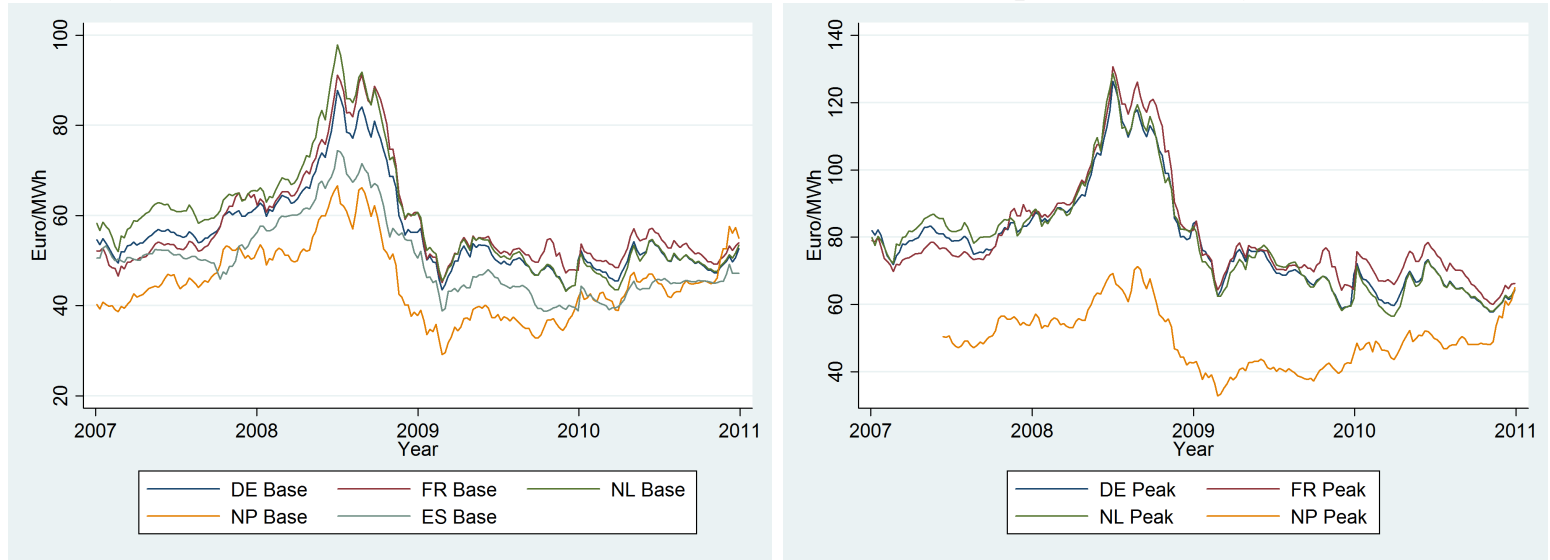

Figure 4: Prices for gas, allowances, coal and German power

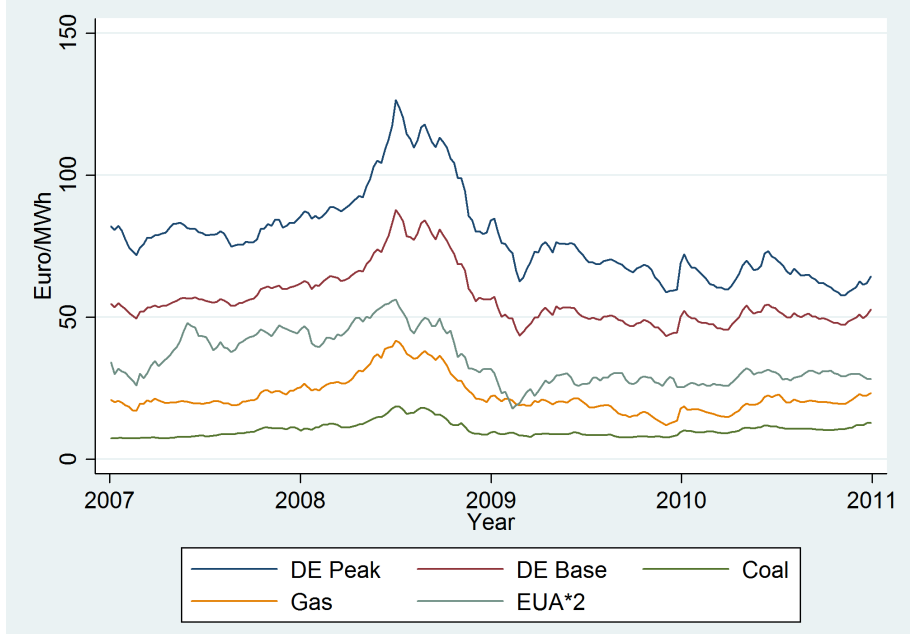

for non-immediate adjustment, we include current as well as lagged input prices. We use the following regression specification:

$$
\begin{aligned}
P_{t}= & \beta_{0} t+\sum_{i=0}^{q_{G}} g_{i} G_{t-i}+\sum_{i=0}^{q_{C}} c_{i} C_{t-i}+\sum_{i=0}^{q_{A}} a_{i} A_{t-i} \\
& +\beta_{1} \text { Res }_{t}+\beta_{2} \text { Spot }_{t}+\beta_{3} \text { Fts }_{t}+\beta_{4}\left(\text { Spot }_{t} \cdot \text { Ftse }_{t}\right)+D_{t}^{M} \beta_{5}+D_{t}^{Y} \beta_{6}+\epsilon_{t} \\
& \epsilon_{t}=\sum_{j=1}^{J} \rho_{j} \epsilon_{t-p}+\sum_{q=1}^{Q} \theta_{q} u_{t-q}+u_{t} \\
& E[\epsilon]=0 ; \quad \operatorname{Var}\left[\epsilon_{t}\right]=\sigma_{t}^{2}=\delta_{0}+\delta_{1} \epsilon_{t-1}^{2} ; \quad E\left[u_{t}\right]=0 ; \quad \operatorname{Var}\left[u_{t}\right]=\sigma_{u}^{2}
\end{aligned}
$$

As control variables, we include current reservoir levels $R e s_{t}$, electricity spot prices Spot $_{t}$ (futures prices could be influenced by spot prices to some extent, especially if traders use heuristics), equity indices $F t s e_{t}$ (stock prices should incorporate all available information about current and expected future economic activity), and interactions between 
the two latter variables (the better the economic outlook, the higher the futures-spot price differential). In addition, we include a set of monthly dummies $\left(D_{t}^{M}\right)$ to adjust for seasonality of expected electricity demand, and yearly dummies $D_{t}^{Y}$ in order to control for expectations related to the future supply of electricity (e.g. the expansion of renewable generation or planned plant maintenance). Since all price series in our sample have unit roots, we take first differences of all variables. ${ }^{89}$

In order to accommodate fat tails in the distribution of price changes, we use an autoregressive conditional heteroskedasticty (ARCH) specification. We additionally allow for autoregressive (AR) and/or moving-average (MA) terms in the error term $\epsilon_{t}$ to correct for autocorrelation. ${ }^{10}$

We estimate (3) separately by electricity market, and by load period (base vs. peak). Equilibrium carbon cost pass-through can be inferred from the sum of the coefficients on current and lagged allowance prices, $a \equiv \sum_{i=0}^{q_{A}} a_{i}$, where $i$ refers to the corresponding lag. Because non-significant lags would cause the estimate for $a$ to be very imprecise, we start with two lags for all input prices and eliminate lags by stepwise reduction until the highest lags are significant at $p<0.05$.

With marginal cost pricing and exogenous input prices, full cost pass-through occurs when $a$ is equal to the average emission intensity of the marginal generators during the respective load period (base or peak). To put our results into perspective, the carbon intensity of a hard coal power plant, an open-cycle gas turbine (OCGT) and a combinedcycle gas turbine (CCGT) is around $0.96 \mathrm{tCO}_{2} / \mathrm{MWh}, 0.6 \mathrm{tCO}_{2} / \mathrm{MWh}$ and $0.42 \mathrm{tCO}_{2} / \mathrm{MWh}$ electricity, respectively, for continuous operation. In the following we focus on the sum of the coefficients on EUA, coal and gas prices. A complete set of coefficient estimates is available from the authors upon request.

We focus on the period after the financial crisis and start all regressions in week 46 of 2008, because log-likelihood tests involving German baseload prices confirmed the pres-

\footnotetext{
${ }^{8}$ We tested for stationarity using the augmented Dickey-Fuller test (with the null hypothesis of a unit root), as well as the KPSS test (with the null hypothesis of stationarity). Both tests are consistent with a unit root.

${ }^{9}$ If all included variables are cointegrated, it is not necessary to first-difference the data, since a linear combination of the variables (and thus the error term) will be stationary. Our cointegration tests indicate that electricity and input prices are indeed cointegrated, but some of the other included variables may not be. As an additional test of cointegration, we estimated (3) in levels. When including only input prices, the results from the levels and the first-difference estimation are identical. However, when including the control variables, the results are no longer the same, indicating that there is no cointegrating relationship between electricity prices, input prices and the control variables.

${ }^{10}$ Note that autocorrelated or nonstationary residuals can be interpreted as a sign of misspecification. Introducing ARMA terms mitigates the effect of this misspecification, but it does not actually address it.
} 
ence of a structural break at this point. ${ }^{11}$ The left panel of Figure 5 shows the marginal effect of the allowance price on electricity 1-year-futures for the five markets in our dataset. The squares refer to the point estimates for $a$, and the bars are the bounds of a 95\% confidence interval.

Figure 5: Marginal effect of the EUA price on electricity prices

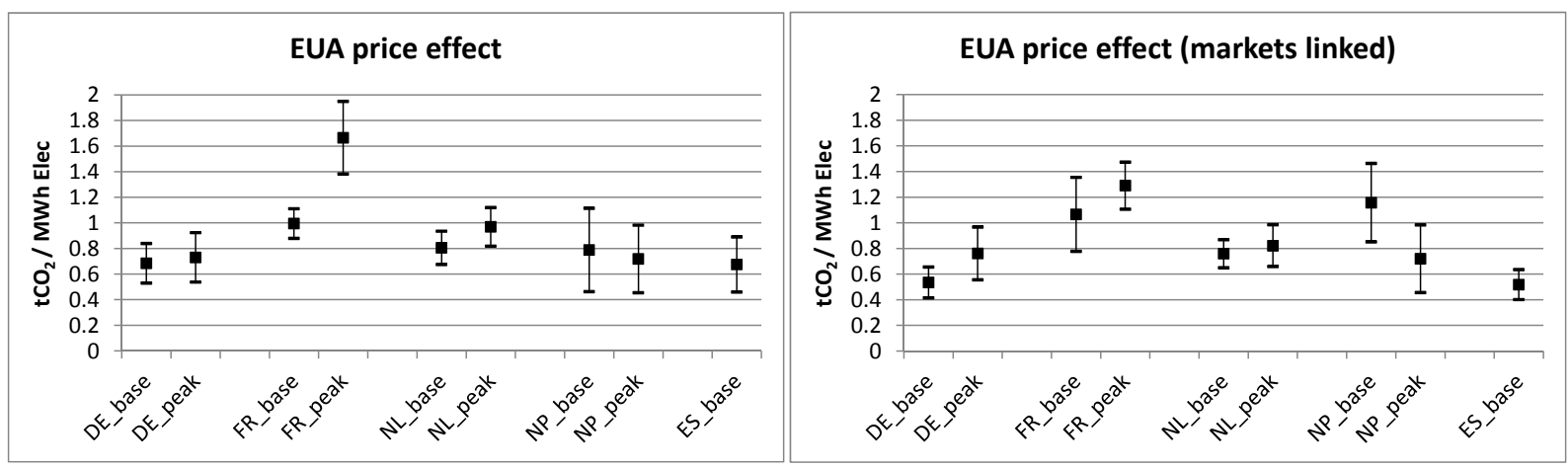

Figure 6: Marginal effect of coal and gas prices on electricity prices

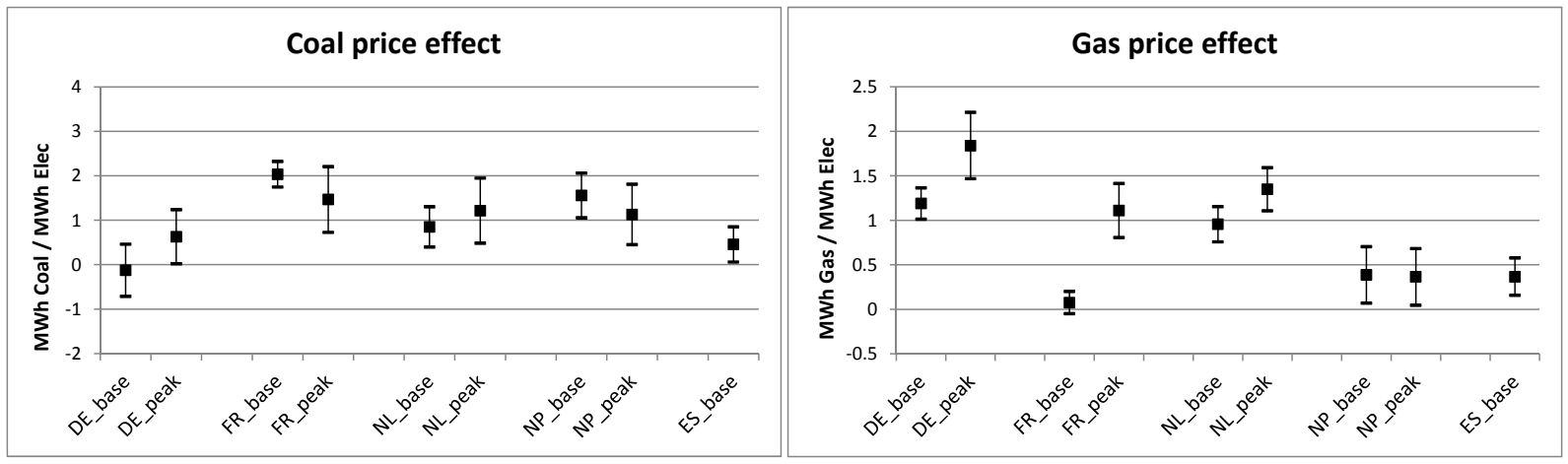

For baseload, cost pass-through is in the range of 0.5-1.1 $\mathrm{tCO}_{2} / \mathrm{MWh}$ electricity for all countries, consistent with coal generation being on the margin during most hours. However, the results for peakload are puzzling. Since peakload electricity is generally assumed to be less carbon-intensive than baseload generation (which in addition to peakload includes off-peak hours) due to a higher gas share, we would expect carbon cost pass-through to be lower for peakload than for baseload. However, the confidence intervals broadly overlap for Germany, the Netherlands and Nord Pool, implying that base and peak electricity prices contain a similar share of carbon costs. For French peakload, carbon cost pass-through falls in the range of 1.4-2.0 $\mathrm{tCO}_{2} / \mathrm{MWh}$, which cannot be ex-

\footnotetext{
${ }^{11}$ For this test we used two model specifications covering the full period. The restricted model contains the variables as outlined in 3, whereas the full model additionally includes a full set of interaction terms with a dummy that is equal to 1 starting in week 46 of 2008, and 0 before. We reject the null hypothesis that all coefficients on the interaction terms are zero at $\mathrm{p}<0.001$. Since the ARCH estimation procedure did not converge, we based the LR-test on an ARIMA $(3,1,3)$. Note that the multi-country cointegration models did not converge at all or led to nonsensical results using the full sample, confirming the presence of a structural break.
} 
plained by marginal cost pricing of fossil generation but is most likely an indication of model misspecification.

One possible explanation for the high carbon cost pass-through during peakload could be an increase in renewable capacity in recent years. Because renewables have very low marginal costs, an additional GWh of renewable generation decreases residual demand for thermal electricity one for one. If renewable generation drives gas out of the system during peakload, it is possible that the marginal generator during an increasing number of hours of peakload is coal. Furthermore, the emission intensity increases when plants are ramped up and down, compared to continuous operation, and this is especially true for coal plants if they are used to meet demand during peak hours. In addition, due to the decrease in the coal/gas price ratio in recent years, coal may have crowded out gas to some extent even in the absence of renewables.

As shown in Figures 1 and 2, renewable supply increased more during peakload than during baseload in Germany and Spain, along with a modest increase in the supply of coalgenerated power. Gas generation decreased significantly, but maintained a non-negligible share of production through 2012. The decrease in German gas generation might have been even more pronounced without the significant decrease in nuclear generation in the wake of the nuclear catastrophe in Fukushima in 2011: Production dropped from 133 TWh in 2010 to 101 TWh in 2011, and to 86 TWh in 2012. Presumably, the decrease in 2011 was not forseeable by traders in 2010 , and they may not have forecasted the full decrease in 2012 in 2011. With more nuclear generation at the bottom of the merit order, the share of gas generation would have been lower, placing coal on the margin during even more hours of the year.

The sensitivity of electricity price futures to the coal price (left panel in Figure 6) is consistent with the hypothesis that coal is on the margin during some peak hours. To get a sense of the magnitude, suppose that the marginal generator is a coal plant with an efficiency of $35 \%$, which is about the average efficiency for coal plants in Europe. ${ }^{12}$ Marginal cost pricing then implies that a $1 €$-increase in the coal price leads to an increase in the electricity price of $1 / 0.35=2.9 € /$ MWh. If coal were never on the margin during peakload, the effect of the coal price should be nil. We could therefore interpret the

\footnotetext{
${ }^{12}$ Plant efficiency is the inverse of the heat rate, defined as heat input/electricity output. An efficiency of 35 $\%$ means that an input of $100 \mathrm{MWh}$ of fuel allows the generation of $35 \mathrm{MWh}$ of electricity. Note that newer coal plants reach efficiencies of well over $40 \%$.
} 
coefficients on coal in the sense that coal appears to be on the margin for between $25 \%$ (DE) to 50\% (FR) of peakload. Interestingly, this is a similar or higher share than that during baseload. Particularly the result for Germany, where coal prices do not appear to affect baseload prices, seems difficult to explain.

On the other hand, peak prices are more sensitive to the gas price in France, Germany and the Netherlands, which implies that gas remains on the margin for a greater share of hours during peakload than baseload, which is inconsistent with similar rates of carbon pass-through.

To test whether our model misses a variable that is both a determinant of electricity prices and correlated with input prices, we ran regressions that additionally included gasoil futures (there is limited generation by oil), renewable generation and reservoir levels in neighboring countries, and stock price indices specific to the electricity sector. However, the qualitative nature of our results was unaffected.

Another source of bias are transmission links between countries. In an effort to gage the relative importance of this particular source of bias, we re-estimated the ARCH models with lagged electricity prices from the neighboring countries included in the regressions. ${ }^{13}$ The results for carbon cost pass-through are displayed in the right-hand panel of Figure 5. They are qualitatively similar to those from the isolated market regressions in the sense that baseload and peakload electricity prices appear to have about the same carbon content. The results for French peakload are less extreme but are still difficult to explain by marginal cost pricing. Nord Pool baseload displays a higher carbon content than in the isolated market setting, and the effect of coal on German baseload is statistically significant, but still lower than during peakload (results not shown but available upon request from the authors). It follows that market links matter, but that allowing for them alone does not lead to results that can be more readily interpreted.

A more likely source of model misspecification lies in the endogeneity of electricity and input prices. The underlying assumption in our ARCH framework is that input prices are exogenous. Referring to eq. (2), this means that we constrain the effect of the carbon price on electricity prices to $\psi$. If electricity and input prices are jointly determined, the coefficients from our ARCH approach could be severely biased. In the next subsections,

\footnotetext{
${ }^{13}$ Lagging neighboring prices is necessary because electricity prices in connected markets are clearly jointly determined. For peakload, we chose to treat the Nord Pool area as disconnected from continental markets due to the sizeable price differentials (Fig. 3), which implies binding transmission constraints.
} 
we treat all price variables as endogenous.

Last, we focus on the effect of coal and gas prices on the allowance price. Although this is not the primary focus of our paper, a literature has emerged that aims to identify the price determinants of allowance prices, in the context of which such an estimate may prove useful. ${ }^{14}$ To this end, we regress

$$
A_{t}=b_{0}+\sum_{i=0}^{q_{G}} \gamma_{i}^{G} G_{t-i}+\sum_{i=0}^{q_{C}} \gamma_{i}^{C} C_{t-i}+b_{1} \text { Res }_{t}+b_{2} \text { Ftse }_{t}+\epsilon_{t}
$$

with $\epsilon_{t}$ as defined in (3). Due to the exogeneity assumption, there is no direct feedback effect from allowance prices to fuel prices, nor an indirect effect via electricity prices (which for this reason are both omitted). Since there is no evidence for a structural break when omitting electricity prices, we use the full sample to estimate (4). The coefficients on lagged fuel prices are not different from zero, rendering the effect of gas and coal prices on the allowance price $\gamma_{0}^{G}=0.39 \mathrm{MWh} / \mathrm{tCO}_{2}(\mathrm{p}<0.001)$ and $\gamma_{0}^{C}=-0.21 \mathrm{MWh} / \mathrm{tCO} 2$ $(\mathrm{p}<0.07)$, respectively. These results are consistent with the hypothesis that $\mathrm{CO}_{2}$ abatement in the EU ETS includes, possibly among other methods, the substitution of coal with gas generation in the electricity sector. The effect of current reservoir levels on EUA futures is not significant, whereas the coefficient on expected future economic activity (as proxied by the German FTSE) is positive and significant. This conforms with expectations, since economic activity has been identified as one of the main drivers of $\mathrm{CO}_{2}$ emissions.

\subsection{Single-market cointegration results}

Unlike the ARCH methods used above that require first-differencing the series to remove stochastic trends, cointegration analysis searches for common stochastic trends among the series, such that linear combinations of the variables result in stationary series. The cointegration analysis thus determines whether the examined price series move together (i.e. if they share a common trend). Furthermore, through the VECM estimation, we do not impose exogeneity of the input prices as was done above.

We estimate the cointegration model using a VECM of the form

$$
\Delta y_{t}=\Pi y_{t-1}^{\star}+\sum_{k=1}^{K} \Gamma_{k} \Delta y_{t-k}+\gamma X_{t}+\epsilon_{t}
$$

\footnotetext{
${ }^{14}$ See, e.g., Aatola et al. (2012); Alberola et al. (2008); Chevallier (2011); Creti et al. (2012); Hintermann (2010, 2012); Mansanet-Bataller et al. (2007); Seifert et al. (2008).
} 
where $y_{t}$ is a vector of the prices (electricity, natural gas, coal, and EUA). The parameter vector $\Pi$ is defined as $\Pi=\alpha^{\prime} \beta$, with $\beta$ being the cointegrating vector describing the long-run relationship between the variables, and $\alpha$ is the loading matrix that determines the speed of adjustment from the long-run relationship. The vector $y^{\star}$ is defined as $y_{t-1}^{\star}=\left[y_{t} 1\right]^{\prime}$ with " 1 " included so that a constant is added to the cointegrating relationship. $\Delta y_{t-k}$ is the $k^{t h}$ lagged first-difference of $y_{t}$ with $\Gamma_{k}$ as the corresponding matrix of parameters. $X_{t}$ is a vector of exogenous variables with parameter vector $\gamma$. For $X_{t}$, we use the same set of exogenous variables as discussed above, namely $X_{t}=\left[\right.$ Res $_{t}$, Spot $_{t}$, Ftse $_{t},\left(\right.$ Spot $_{t} \cdot$ Ftse $\left.\left._{t}\right), D_{t}^{M}, D_{t}^{Y}\right]$.

We start by using a cointegration framework for single markets, before extending it to multiple electricity markets. We first determine the cointegrating rank (i.e., number of cointegrating relationships) embodied in $\beta$. The rank is determined using the Johansen trace and maximum-eigenvalue tests (for details, see Johansen, 1996). ${ }^{15}$

Results from these tests are given in Table 2. Because the conclusions drawn from the trace and maximum-eigenvalue tests are the same for this application, we report only the trace-test statistics. The results suggest that for most country-markets (base or peak) there appears to be a single cointegrating relationship among the electricity price and the input prices of natural gas, coal, and EUA's. ${ }^{16}$ The exceptions are ES-Base and, at least at the 10 percent significance level, DE- and NP-Peak. These country-markets appear to have up to two cointegrating relationships among the four price series. These exceptions are somewhat perplexing. The results for DE-Peak, NP-Peak and ES-Base suggest that there is a cointegrating relationship between the given electricity prices and at least some of the input prices and another cointegrating relationship among the input prices. Given that the analyses of the other country-markets do not pick up such an input-price-only cointegrating relationship, it seems unlikely that it exists. ${ }^{17}$ We therefore proceed under the assumption that each country-market has a single cointegrating vector among electricity, natural gas, coal, and EUA prices.

From the parameter estimates of the VECMs, we can estimate the response of electric-

\footnotetext{
${ }^{15}$ To choose the lag length for the lagged, first-differenced vector of dependent variables needed in the auxiliary regression, we used the BIC model selection criteria.

${ }^{16}$ The null hypothesis of Johansen's rank tests is that $\operatorname{rank}\left(\alpha \beta^{\prime}\right) \leq r$. Thus, as is common practice, we conclude that the rank of $\alpha \beta^{\prime}$ is the first $r$ value where the test fails to reject the null.

${ }^{17}$ It is possible that the results from the other markets pick up an input-price-only cointegrating relationship and no relationship with the electricity prices; however, looking at the parameters of the cointegrating vector, we find statistically significant parameters when normalizing on electricity prices. This suggests that the electricity prices are not being "zeroed-out" of the cointegrating vector.
} 
Table 2: Individual Country Cointegration Rank Test

\begin{tabular}{cccccccccc}
\hline & DE-Base & DE-Peak & NP-Base & NP-Peak & NL-Base & NL-Peak & FR-Base & FR-Peak & ES-Base \\
\hline$r=0$ & $62.9^{* *}$ & $81.2^{* *}$ & $58.4^{* *}$ & $52.6^{* *}$ & $76.6^{* *}$ & $68.1^{* *}$ & $76.0^{* *}$ & $81.9^{* * *}$ & $62.9^{* * *}$ \\
$r=1$ & 21.5 & $28.6^{*}$ & 29.8 & $29.9^{*}$ & 25.9 & 26.5 & 23.0 & 23.0 & $31.6^{* * *}$ \\
$r=2$ & 9.9 & 10.5 & 12.3 & 11.4 & 11.8 & 11.7 & 12.2 & 12.6 & 10.4 \\
$r=3$ & 1.4 & 2.1 & 1.8 & 1.6 & 2.1 & 5.7 & 2.5 & 2.9 & 0.9 \\
\hline
\end{tabular}

Note: The null hypothesis is $\operatorname{rank}\left(\alpha \beta^{\prime}\right) \leq r$. "**" and "*" denote rejection of the null hypothesis at the $5 \%$ and $10 \%$ significance levels, respectively.

ity prices to a shock in EUA prices, accounting for the relationships across all prices in the system, through the use of impulse response analysis. There are several ways to compute impulse responses. We use the generalized impulse response form (GIRF) of Pesaran and Shin (1998), which accounts for covariance terms in $\Omega$ when tracing out the responses to a given shock. In addition, the ordering of the prices in $y_{t}$ does not matter when using GIRF, unlike when using standard or orthogonalized impulse response forms.

Figure 7 traces out the response of base and peak electricity prices to a $1 €$-shock to EUA prices at time zero, based on the individual-country VECM analyses. Similarly, Figures 8 and 9 contain the plots of base and peak electricity price responses to a shock in coal and natural gas prices, respectively.

Figure 7: Responses to a 1-€-shock to EUA prices

Base Electricity Price Response to 1Euro EUA Price Shock

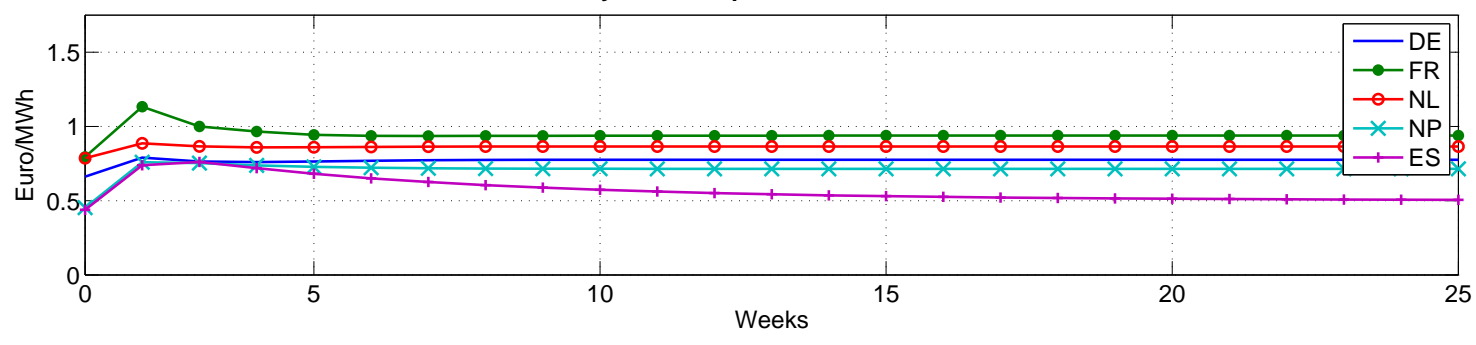

Peak Electricity Price Response to 1Euro EUA Price Shock

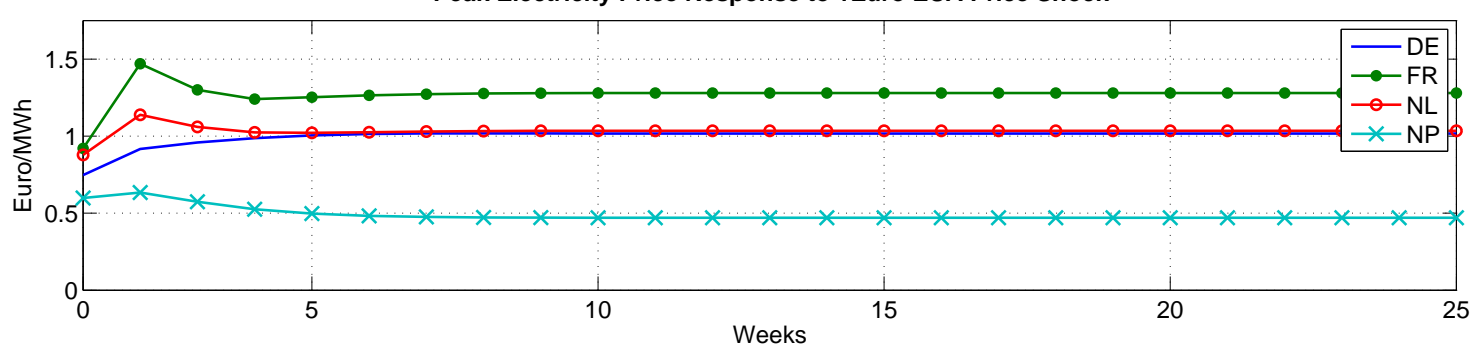

Baseload electricity price responses to a one-time EUA price shock stabilize at 0.5 $€ /$ MWh for Spain, and around 0.7-0.9 €/MWh for the other countries in our sample. This is consistent with full pass-through of carbon costs associated with baseload generation. The lower carbon content in Spain could be explained by the high share of gas generation 
Figure 8: Responses to a 1-€-shock to coal prices

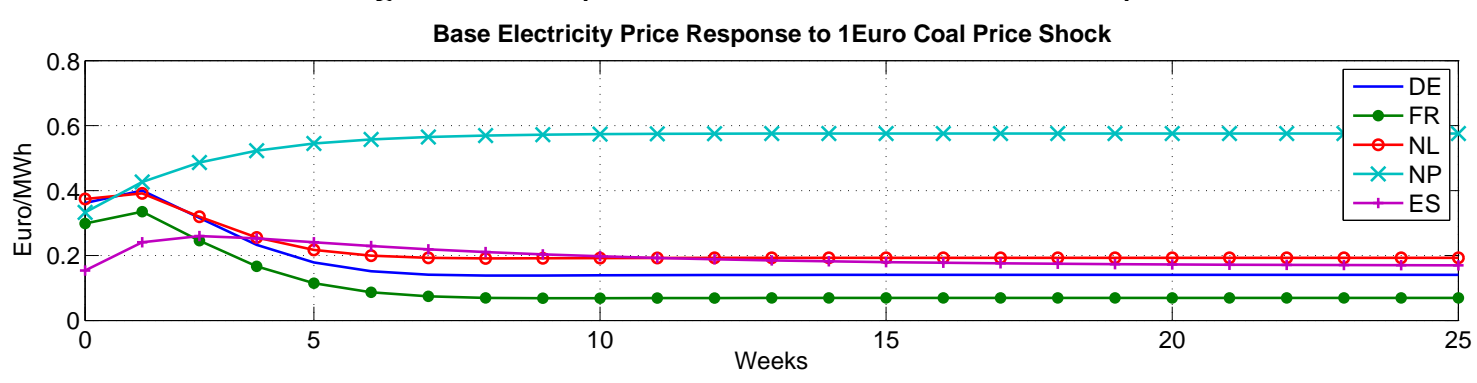

Peak Electricity Price Response to 1Euro Coal Price Shock

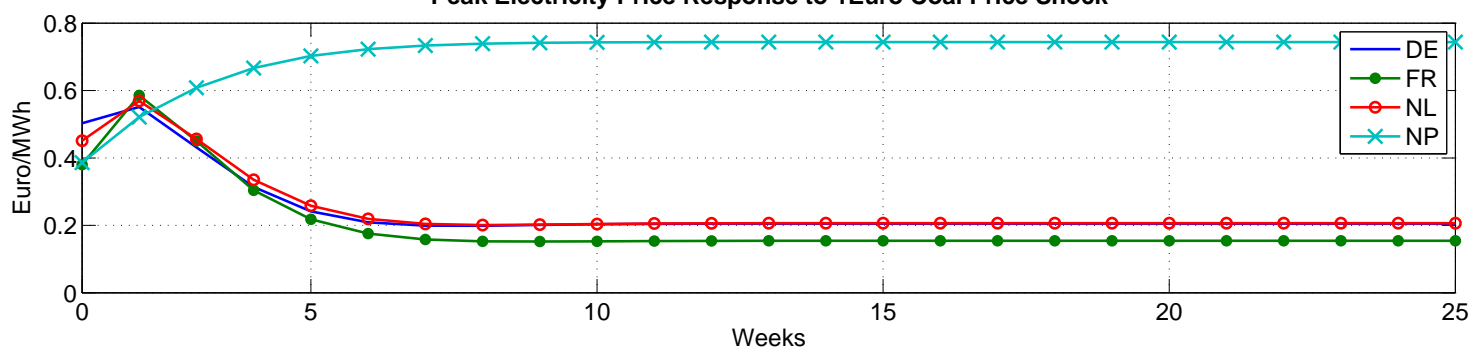

Figure 9: Responses to a 1-€-shock to natural gas prices
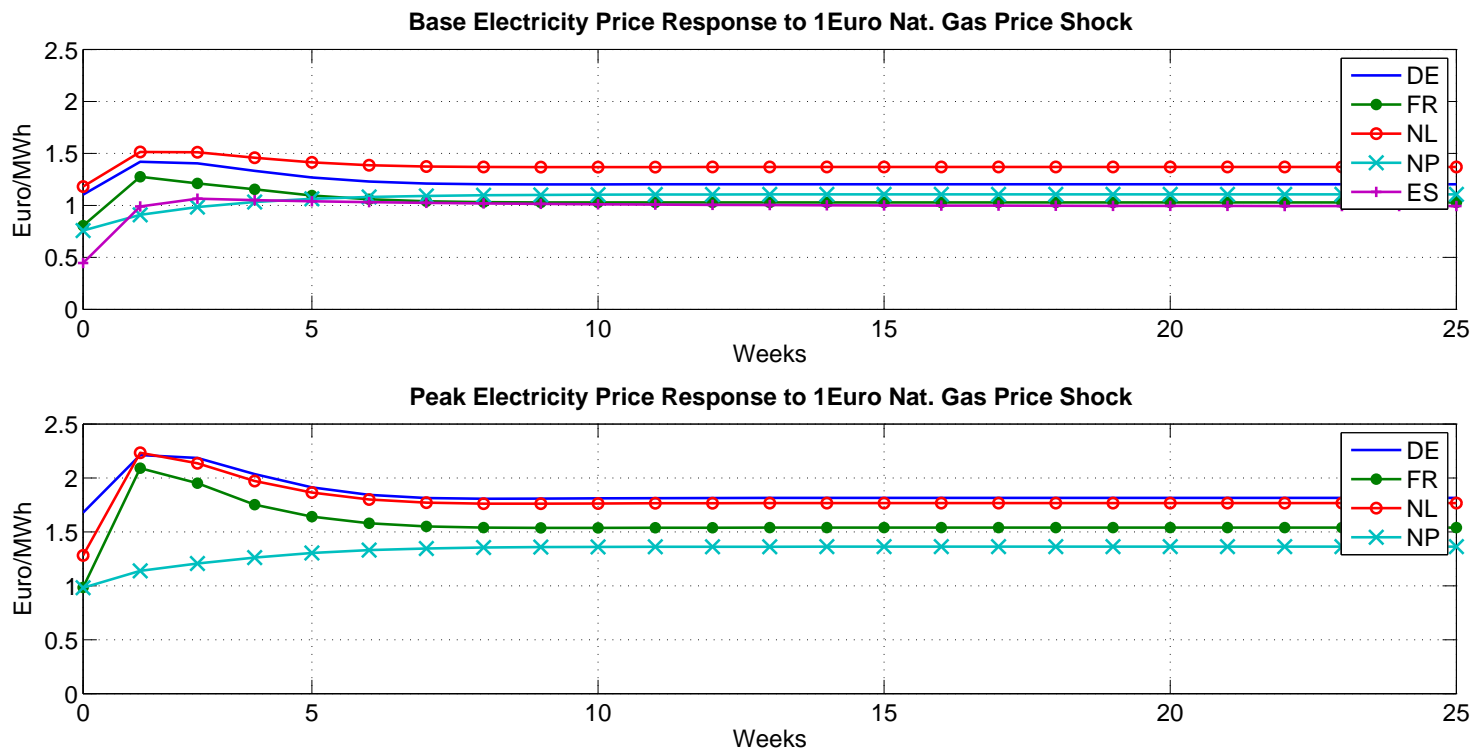

in combination with transmission constraints to the continental markets. ${ }^{18}$

Peak price responses in the Nordic area are lower than baseload responses and are therefore consistent with a higher share of gas generation during peakload periods; this also corroborates the results obtained by Fell (2010) for this market. For Germany and the Netherlands, the electricity price response to a carbon price shock is about the same during peakload as during baseload, which is contrary to conventional wisdom but consistent with our ARCH results. Again, the hypothesis that expected renewable generation drives gas partially out of the market and leaves coal on the margin more frequently is

\footnotetext{
${ }^{18}$ With unconstrained transmission and thus fully integrated electricity markets, there would be only one marginal generator for the entire market. However, transmission constraints exist, and they are binding during a significant number of hours during the year.
} 
again consistent with electricity price responses to a shock in the coal price, which are similar for baseload and peakload.

French peakload seems more responsive than baseload to a shock in carbon and coal prices, which is difficult to explain by marginal cost pricing, as is the fact that the Nordic response to coal is higher than for all other countries. However, we emphasize the caveat that these peak price responses are based on system estimators that have many complicated price feedbacks, and that they do not explicitly account for possibly relevant cross-country correlations.

Moving on to the electricity price responses to natural gas, we find some initial heterogeneity in the electricity price responses to a $1-€$-shock in the natural gas price for both peak and base price series, but the longer-run responses are relatively similar across countries. The base-price response for a given country is generally lower than that for the corresponding peak-price response.

Overall, our single-country cointegration results are quite similar to the ARCH results for France, Germany and the Netherlands, whereas the endogenous treatment of input prices seems to have improved the estimates for the Nordic area and for Spain.

\subsection{Multi-Country Cointegration Analysis}

As noted above, there could be inter-country correlations present that are not explicitly accounted for in the individual country results. Such correlations may bias the results presented in the country-by-country analyses given above. We therefore consider systems where instead of looking for cointegrating relationships between a single country's electricity price and natural gas, coal and EUA prices, we add multiple electricity price series along with the natural gas, coal, and EUA prices to the $y_{t}$ vector. With multiple electricity prices in the $y_{t}$ vector, interactions across prices from the various included electricity markets are allowed in several ways.

First, the short-run dynamics captured by the off-diagonal elements of $\Gamma_{k}$ can allow for one country's current electricity prices to react to changes in other countries' prices. Second, off-diagonal elements of $\Omega$ allow for shocks in one country's electricity price to transmit to other countries. Third, if the countries' electricity prices have independent long-run relationships with the input prices, then non-zero off-diagonal elements of the loading matrix $\alpha$ can create a situation where a given country reacts to the long-run dis- 
Table 3: Multi-Country Cointegration Rank Tests

Base Peak

\begin{tabular}{ccc} 
Grouping: & DE,ES,FR,NP,NL & DE,NP,NL,FR \\
\hline$r=0$ & $241.3^{* *}$ & $220.4^{* *}$ \\
$r=1$ & $166.8^{* *}$ & $131.9^{* *}$ \\
$r=2$ & $101.8^{* *}$ & $75.6^{* *}$ \\
$r=3$ & 66.8 & 42.1 \\
$r=4$ & 38.9 & 20.0 \\
$r=5$ & 21.9 & 9.7 \\
$r=6$ & 10.5 & 2.9 \\
$r=7$ & 4.9 & - \\
\hline
\end{tabular}

Note: The null hypothesis is $\operatorname{rank}\left(\alpha \beta^{\prime}\right) \leq r$. "**" and "*" denote rejection of the null hypothesis at the $5 \%$ and $10 \%$ significance levels, respectively.

equilibrium in another country's long-run relationship. Finally, there may be situations where each country does not have an independent long-run relationship between its electricity price and the input prices. That is, in a $y_{t}$ vector that includes $N$ electricity prices and the input prices, we may find a cointegrating rank less than $N$, resulting in a likely triangular representation in which multiple electricity prices are in the same long-run relationship.

To begin the multi-country analysis, we again conduct Johansen trace tests. This is conducted for the baseload price grouping, where all the available prices are included in $y_{t}$ (i.e., $y_{t}=\left[P_{t}^{D E}, P_{t}^{E S}, P_{t}^{F R}, P_{t}^{N L}, P_{t}^{N P}, G_{t}, C_{t}, A_{t}\right]^{\prime}$ for baseload), and for the peakload grouping, which is the same as that for baseload, with the exclusion of Spanish prices due to data availability. The results from the trace tests are given in Table 3. The table gives the "country groupings" in the header of each column, which denote the electricity price series included in the $y_{t}$ vector along with the natural gas, coal, and EUA price series. Below these headers are the Johansen trace statistics.

For both the peak and base price groupings we find evidence of three cointegrating relationships among the electricity prices and input fuel prices and thus fewer than among the number of included electricity prices in the $y_{t}$ vector. This suggests that beyond the possibility for short-run interactions among the markets, some markets may interact within a long-run relationship as well.

Applying the results of the cointegrating rank tests, we estimate the VECMs for the base and peak specifications and use these estimated parameters to form the impulse responses. The plots of the impulse responses are shown in Figure 10, with base price responses in the top panel of and peak price responses in the bottom panel. In order to 
assess the statistical significance of the responses, we plot the long-run responses along with the corresponding boot-strapped, 95-percent confidence intervals in Figure $11 .{ }^{19}$

Figure 10: Multi-Country Electricity Price Responses to EUA Price Shock

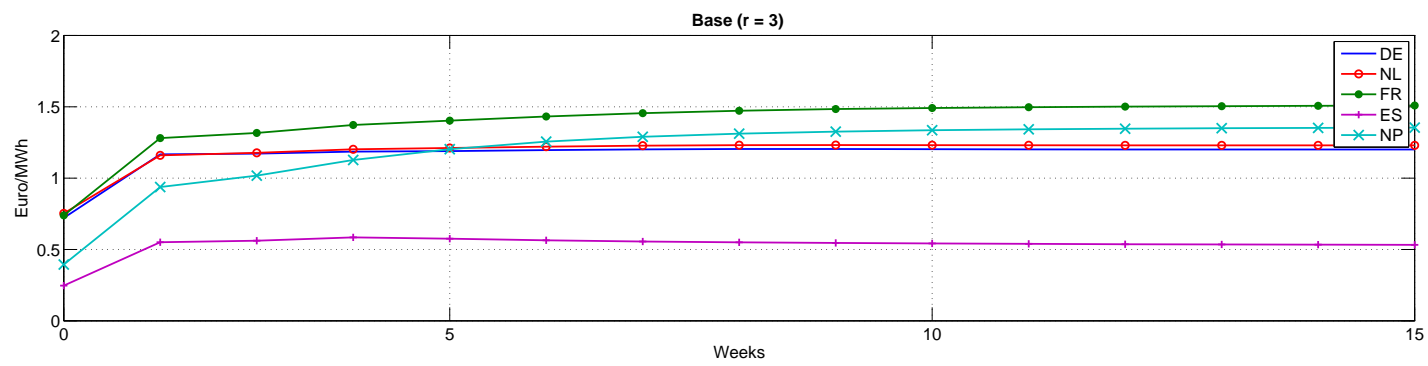

Peak $(r=3)$

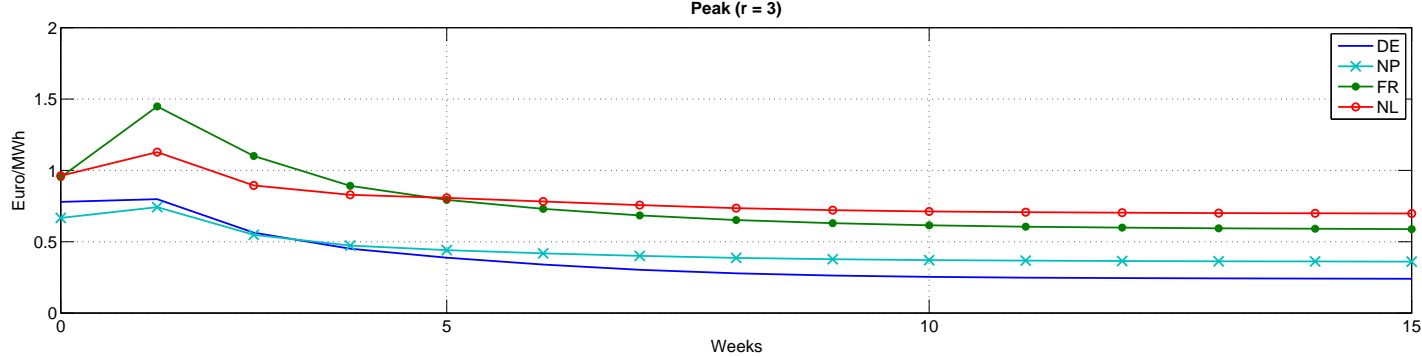

For the base price responses, we find all countries except Spain level off in the range between $1.2-1.5 € / \mathrm{MWh}$. These responses are similar to the corresponding responses from the individual analysis. The base price response for Spain is, however, considerably lower than for the other countries, with a response stabilizing near $0.5 € / \mathrm{MWh}$. We might expect a lower response for base prices in Spain given its relatively high percentage of natural gas-fired generation as shown in Figure 1.

Consistent with the ARCH model and individual-country cointegration results shown above, the peak price responses for the multi-country analysis start near or above where the base price responses begin, but then stabilize at levels around $0.5 € / \mathrm{MWh}$. This is more in line with the expectations that natural gas generators are the price-setting generators during peak hours. Also, from Figure 11, we find that peak and base responses for DE, FR, NL, and NP appear to be statistically different from one another in the long run (i.e., the respective 95 percent confidence intervals for base and peak price responses do not overlap). It is also worth noting that while the peak responses from DE and NP in the long run are not statistically different from zero based on the 95 percent confidence intervals, the confidence intervals for all peak price response in the long run do encompass the responses one would expect to find in a competitive market with natural gas generation

\footnotetext{
${ }^{19}$ The long-run responses are the impulse response estimates, with 95 percent confidence intervals, at 15 periods after the initial EUA price shock. By this period, all responses have stabilized.
} 
Figure 11: Long-run Responses

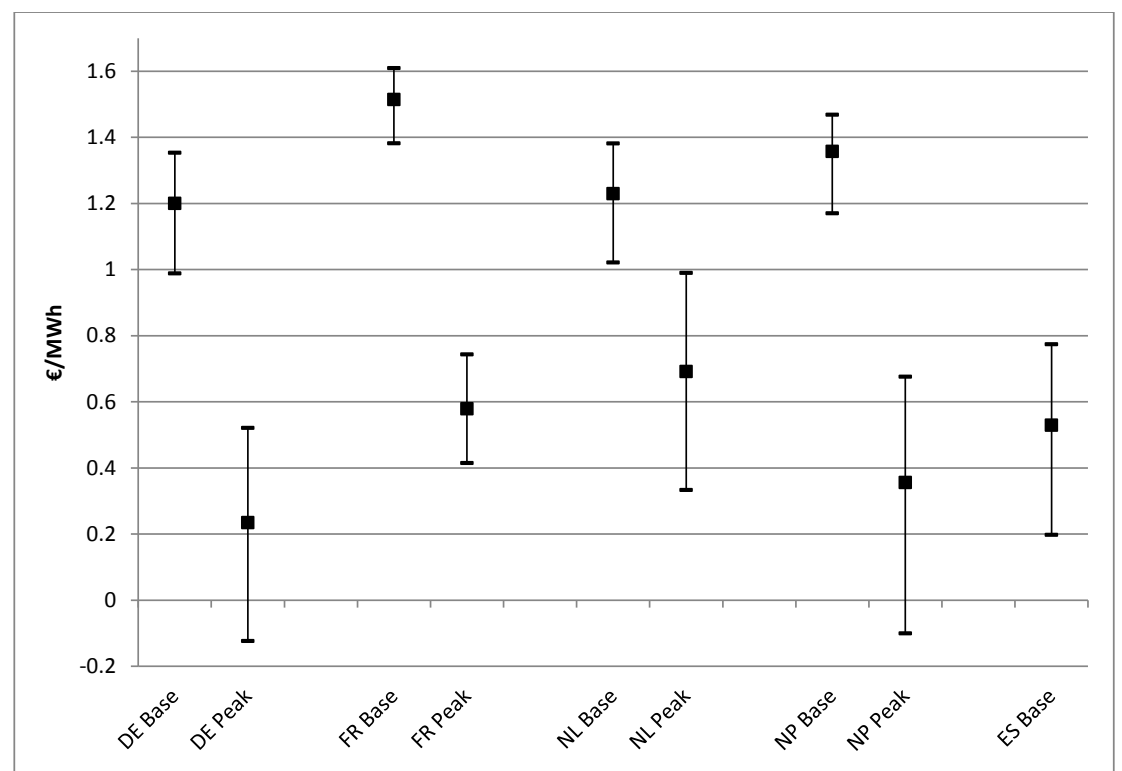

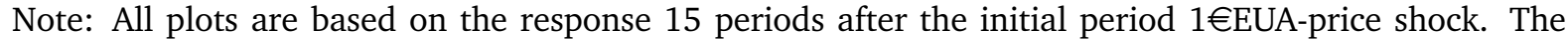
95 percent confidence intervals are determined by the bootstrapping method described in Lütkepohl (2005).

on the margin. Our multi-country cointegration results are therefore not inconsistent with full cost pass-through based on marginal cost pricing, but the variance of our estimates does not allow for a more precise determination of the level of cost pass-through.

Finally, through the estimated VECM, we can also ascertain the effect of coal and natural gas price shocks on EUA prices. The response of EUA prices to a shock in natural gas and coal prices is plotted in Figure 12. These responses are based on the multi-country, base-price estimation, since the base includes all hours of the day. Consistent with the findings presented in subsection 4.1, Figure 12 shows that a positive coal price shock lowers the EUA price, whereas an increase in natural gas prices increases it. However, the 95 percent confidence intervals for the EUA response to natural gas prices is quite large and shows the response is not statistically different from zero.

\section{Discussion}

We analyze the relationship between electricity and input prices, including the cost of $\mathrm{CO}_{2}$ emissions for five European electricity markets, based on one-year futures and using three different approaches: A single-country, exogenous-price framework, a single-country cointegration model with endogenous prices, and finally a multi-country cointegration frame- 
Figure 12: EUA Price Response to Natural Gas and Coal Price Shocks

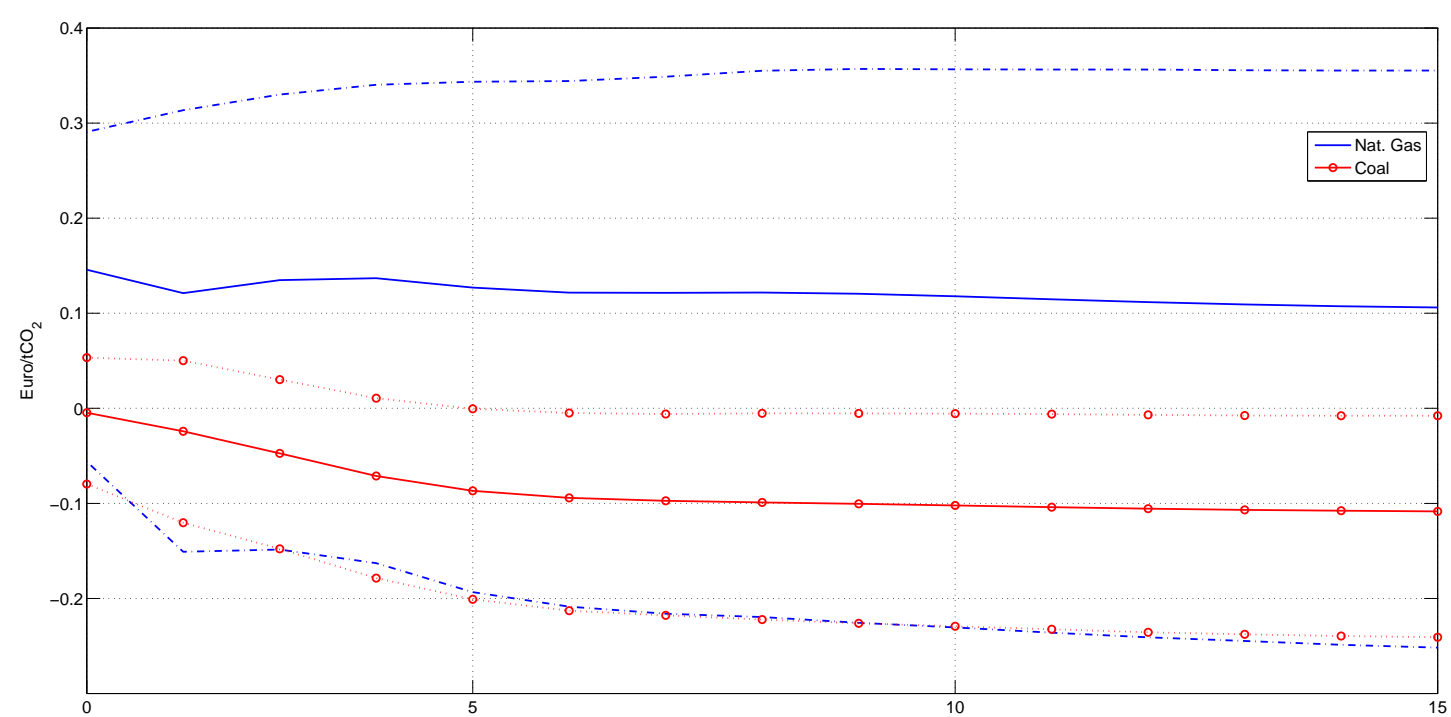

Note: The responses are based on the multi-country, base-price estimation. The solid lines represent the estimated responses and the 95 percent confidence intervals are given as dashed lines. For the response to a coal price shock, the estimated response and confidence intervals have a circle marker.

work. In this transition from more simple to more complex modeling, we face a tradeoff. On the one hand, the assumptions placed on the underlying data-generating processes are relaxed by allowing for price endogeneity and cross-market cointegration. On the other hand, the more complex models make it impossible to interpret any single coefficient, and we have to rely on long-term impulse-response functions that are the product of a series of complex interactions among all variables. These models are also sensitive to the selection of included countries and to exogenous shocks and regime shifts. In other words, we have to choose between simple models that tend to place excessively stringent assumptions on the data, and complex models that "let the data speak for themselves" and produce results that are difficult to interpret and less robust.

Our results from the exogenous-price framework suggest that base price responses to an EUA price increase are in line with expectations assuming that coal-fired plants are most often the marginal generator during base hours. However, this framework found the peak-price responses to EUA price shocks to be approximately of the same magnitude as the base-price response. This result does not adhere to expectations, as it is typically thought that natural-gas-fired generators are on the margin during a significant fraction of peak hours; hence we would expect responses to be lower in the peak periods given natural gas has a lower carbon content. A possible explanation of the higher-than-expected carbon content of peak prices is that the influx of renewables has driven gas partially out 
of the market, which is consistent with the sensitivity of the peak price to coal prices, as well as the decline in the share of natural gas in overall generation during peakload. On the other hand, peak prices are more sensitive to the gas price than to the coal price, indicating that gas still plays an important role during at least a portion of peakload hours.

Another possible explanation could lie in the fact that we base our analysis on future prices in order to abstract from contemporaneous shocks to electricity demand and supply. Future prices do not reflect actual marginal costs of generation, but traders' expectations of these marginal costs. In addition, future prices are used to hedge against price risk. It is therefore possible that the relationship between carbon and electricity prices is different for futures and for "actual" prices, i.e. spot prices, and that this causes the high passthrough rates we observe. The analysis of carbon cost-pass through based on spot market data using cointegration models could therefore prove a fruitful topic of future research.

The results from the single-country cointegration framework are largely consistent with the exogenous-price framework. The exception is the Nord Pool market where the single-country cointegration analysis estimated the peak-price response to an EUA price shock to be lower than that for the base-price response and the magnitude of both responses to be more in line with expectations.

In the multi-country cointegration analysis, our results are more in line with expectations. We find that, when using a specification which includes all available peak or base electricity prices, along with the input prices, in the the dependent-variable vector, peak-price responses to an EUA price shock in DE, FR, NL, and NP are, at least in the long run, significantly lower than their corresponding base price responses. However, the peak price responses in the short run appear to be as high as the base responses.

Our tests imply that electricity and input prices are cointegrated for each electricity market, and that some of the electricity prices themselves are also cointegrated. This could be interpreted as an indication that price endogeneity and market cointegration are sufficiently relevant to warrant the use of models that take these features into account. At the same time, the sensitivity of the results to the inclusion of other countries raises concerns about the robustness of these results, as does the imprecision of the estimates.

Finally, as noted above, the results for the Nordic area are most in line with expectations when using a single-country cointegration framework, i.e. when not allowing for cross-market relationships. Although there may be alternative interpretations, this may 
be a sign of imperfect integration within European electricity markets due to transmission constraints. Allowing for cross-market links that are not effective during many hours (as evidenced by the price differential between Nordic and continental European peakload prices) may introduce spurious cross-market relationships and bias the impact-response functions. Incorporating specific transmission constraints into the cointegration model could address this issue, but this would not only be econometrically challenging, but also require information about the expected stringency of transmission constraints for each hour and some function to aggregate this information into weekly averages.

Overall, our results imply complete pass-through of carbon costs in Phase II of the EU ETS, which is an indication for marginal cost pricing and thus for competitive markets. In contrast, a monopolist would pass through only a part of the carbon cost increase while trimming the profit margin in order to preserve the equality between marginal revenue and marginal cost.

Last, our results relating to the effect of fuel prices on the EUA price are consistent with the hypothesis that fuel switching is an important source of abatement: An increase in the price for natural gas (coal) makes this switch more (less) costly. Even if fuel switching may not be profitable at the low EUA prices towards the end of the phase, the banking provision allows for intertemporal arbitrage, implying that the allowance price could be equal to the discounted future cost of abatement.

\section{References}

Aatola, Piia, Markku Ollikainen, and Anne Toppinen (2012) "Price determination in the EU ETS market: Theory and econometric analysis with market fundamentals," Energy Economics.

Alberola, Emilie, Julien Chevallier, and Benoît Chèze (2008) "Price drivers and structural breaks in European carbon prices 2005-2007," Energy Policy, Vol. 36, No. 2, pp. 787797.

Bosco, Bruno, Lucia Parisio, Matteo Pelagatti, and Fabio Baldi (2010) "Long-run relations in European electricity prices," Journal of Applied Econometrics, Vol. 25, No. 5, pp. 805832. 
Bovenberg, A. Lans and Lawrence H. Goulder (2000) "Neutralizing the Adverse Industry Impacts of CO2 Abatement Policies: What Does It Cost?". Resources for the Future Discussion Paper 00-27.

Chevallier, Julien (2011) "A model of carbon price interactions with macroeconomic and energy dynamics," Energy Economics, Vol. 33, No. 6, pp. 1295-1312.

Creti, Anna, Pierre-André Jouvet, and Valérie Mignon (2012) “Carbon price drivers: Phase I versus Phase II equilibrium?" Energy Economics, Vol. 34, No. 1, pp. 327-334.

Fell, Harrison (2010) "EU-ETS and Nordic Electricity," Energy Journal, Vol. 31, No. 2, pp. $1-26$.

Fezzi, Carlo and Derek W. Bunn (2010) "Structural Interactions of European Carbon Trading and Energy Prices," Journal of Energy Markets, Vol. 2, No. 4, pp. 53-69.

Hintermann, Beat (2010) "Allowance Price Drivers in the First Phase of the EU ETS.," Journal of Environmental Economics and Management, Vol. 59, No. 1, pp. 43 - 56.

(2011) "Market Power, Permit Allocation and Efficiency in Emission Permit Markets," Environmental and Resource Economics, Vol. 49, No. 3, pp. 327-349.

(2012) "Pricing emission permits in the absence of abatement," Energy Economics, Vol. 34, No. 5, pp. 1329-1340.

Johansen, Soren (1996) Likelihood-Based Inference in Cointegrate Vector Autoregressive Models: Oxford University Press.

Lise, Wietze, Jos Sijm, and Benjamin F. Hobbs (2010) “The impact of the EU ETS on prices, profits and emissions in the power sector: simulation results with the COMPETES EU20 model," Environmental and Resource Economics, Vol. 47, No. 1, pp. 23-44.

Lo Prete, Chiara and Catherine S Norman (2012) "Rockets and feathers in power futures markets? Evidence from the second phase of the EU ETS," Energy Economics.

Lütkepohl, Helmut (2005) "New introduction to multiple time series analysis."

Mansanet-Bataller, Maria, Angel Pardo, and Enric Valor (2007) “CO2 Prices, Energy and Weather.," Energy Journal, Vol. 28, No. 3, pp. 73 - 92. 
Pesaran, Hashem and Yongcheol Shin (1998) "Generalized Impulse Response Analysis in Linear Multivariate Models," Economics Letters, Vol. 58, No. 1, pp. 17-29.

Seifert, Jan, Marliese Uhrig-Homburg, and Michael Wagner (2008) "Dynamic Behavior of CO2 Spot Prices.," Journal of Environmental Economics and Management, Vol. 56, No. 2, pp. $180-194$.

Sijm, Jos, S. Hers, Wietze Lise, and B. Wetzelaer (2008) "The impact of the EU ETS on electricity prices." Final report to DG Environment of the European Commission.

Sijm, Jos, Karsten Neuhoff, and Yihsu Chen (2006) "CO2 Cost Pass Through and Windfall Profits in the Power Sector," Climate Policy, Vol. 6, No. 1, pp. 49-72.

Smale, Robin, Murray Hartley, Cameron Hepburn, John Ward, and Michael Grubb (2006) "The impact of $\mathrm{CO} 2$ emissions trading on firm profits and market prices," Climate Policy, Vol. 6, No. 1, pp. 29-46.

Zachmann, Georg and Christian von Hirschhausen (2008) "First evidence of asymmetric cost pass-through of EU emissions allowances: Examining wholesale electricity prices in Germany," Economics Letters, Vol. 99, No. 3, pp. 465-469. 